\title{
Outcome of ventilation in patients with hypercapnic respiratory failure in IPF patients: A prospective study
}

\author{
Manjunath Hunasenahalli Krishnappa ${ }^{1}$, Prasanna Kumar Thimmarayappa², \\ Vivek Nangia ${ }^{3}$, Rajat Chatterji ${ }^{4}$ \\ ${ }^{1}$ Senior Resident, ${ }^{2}$ Associate Professor, Department of Respiratory Medicine, M S Ramaiah Medical college, MSR \\ Nagar, MSRIT Post, Bengaluru, ${ }^{3}$ Principal Director and Head, Pulmonology, Max Super-Specialty Hospital, Saket, \\ New Delhi, ${ }^{4}$ Senior Consultant, Fortis Hospital, Vasant Kunj, New Delhi
}

\section{A B S TR A C T}

Background: Diffuse parenchymal lung disease (DPLD) is the inflammation and fibrosis of lung interstitium, resulting in respiratory failure. The rate of hypoxic respiratory failure is high as the disease progresses. In idiopathic pulmonary fibrosis (IPF) patients, acute deterioration leads to type 2 respiratory failure, etiology and management of which remains to be completely understood. Aims and Objectives: To identify the causes of type 2 respiratory failure and assess the outcome of invasive and non-invasive ventilation in patients with IPF. Materials and Methods: This prospective single center study included $>18$-year-old 44 patients with IPF. History of patients, complete blood count, chest radiograph, urine routine, spirometry with bronchodilator reversibility, DLCO (diffusing capacity for carbon monoxide) testing, arterial blood gas measurements, and antinuclear antibody (ANA) test were evaluated. Results: Fourteen (31.8\%) patients developed type 2 respiratory failure (within 1.5-6 years from the time of onset of illness). Causes of respiratory failure included acute exacerbation of IPF (35.71\%), infections $(14.29 \%)$, heart failure $(14.29 \%)$, ischemic heart disease (14.29\%), pulmonary embolism (21.43\%), pneumothorax (7.14\%), and surgical lung biopsy (7.14\%). Patients were initiated on non-invasive mechanical ventilation (NIV) $(64.29 \%)$ and invasive mechanical ventilation (IMV) $(35.71 \%)$. Eight $(88.89 \%)$ out of 9 patients on NIV survived, whereas all 5 patients $(100 \%)$ on IMV expired. Conclusion: Considering the higher mortality rate associated with IMV, NIV is a better technique than IMV for improving patient outcome and management. NIV may be effectively implemented for improving the treatment outcome in patients with IPF and avoiding any aggressive therapeutic approaches.

\section{Access this article online}

Website:

http://nepjol.info/index.php/AJMS DOI: 10.3126/ajms.v12i9.37155 E-ISSN: 2091-0576

P-ISSN: 2467-9100

Copyright (c) 2021 Asian Journal of Medical Sciences

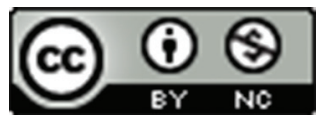

This work is licensed under a Creative Commons Attribution-NonCommercial 4.0 International License.

Key words: Adolescent; Artificial respiration; Bronchodilator agents; Idiopathic pulmonary fibrosis; Interstitial lung diseases; Noninvasive ventilation; Respiratory insufficiency

\section{INTRODUCTION}

DPLD comprises of several group of diseases, which are characterized by inflammation of lung interstitium or parenchyma and varying degree of fibrosis. ${ }^{1}$ The interstitium is stated as a region between the pulmonary vascular endothelium and alveolar epithelium that consists of several kinds of cells such as fibroblasts, myofibroblasts, macrophages along with extracellular matrix components including collagens, elastin, and proteoglycans. ${ }^{1}$ Many patients do not respond to treatment when oxygen capacity of lungs decreases drastically, and patients have difficulties in performing daily routine activities. Couple of decades back, DPLD was considered as a rare disease but now respiratory physicians encounter many cases of DPLD. ${ }^{1}$ Manifestation of DPLD symptoms vary between patients. Around 200 etiological factors were identified for DPLD. ${ }^{2}$ Interstitial lung diseases (ILD) can be broadly classified into four types: (a) disorders with known causes i.e., connective tissue disease including rheumatoid arthritis, systemic sclerosis, systemic 
lupus erythematosus, dermatomyositis or polymyositis and Sjogren's syndrome; (b) disorders with unknown causes i.e., idiopathic interstitial pneumonia (IIP); and (c) granulomatous ILD such as hypersensitivity pneumonitis and sarcoidosis, and (d) rare forms (LAM and LCH). ${ }^{3}$

The different causes of respiratory failure in IPF are acute exacerbation of DPLDIF, opportunistic infections in IPF, heart failure, ischemic heart disease, pulmonary embolism, pneumothorax, pulmonary hypertension, surgical lung biopsy, bronchial carcinomas, other causes including adverse effect of drugs, concomitant obstructive sleep apnea, concomitant chronic obstructive pulmonary disease etc. ${ }^{4}$ In India, earlier IPF was known as a rare disease, but this scenario has been changed over the few decades. ${ }^{5}$ Results of a prospective registry of ILD cases in India registered 1084 cases over a span of 3 years, 3 months (March 2012-June 2015) from 27 centers across 19 Indian cities. The prevalence of IPF has a $0.5-27 / 100,000$ and an incidence of $0.22-8.8 / 100,000$ inhabitants worldwide. ${ }^{6}$ Antifibrotic agents Pirfenidone and Nintedanib are approved drugs for IPF, while steroids can be useful during acute non-infective exacerbations. Lung transplantation is only hope for patients having progressive deterioration while on medical treatment. ${ }^{5} \mathrm{~A}$ better understanding of etiological factors, diagnosis and prognosis is required to develop management strategies to tackle IPF. The current research is one such initiative to know the various causes of the respiratory failure and its management in case of IPF.

\section{MATERIALS AND METHODS}

The patients were recruited from the Department of Pulmonology of Fortis Hospital, Vasant Kunj, New Delhi between May 2012 to May 2014. The study protocol was duly approved by Institutional Medical Ethics Committee (IMEC) and conducted in accordance with the Helsinki Declaration of 1975 , as revised in 1983 . The study was conducted after receiving the duly signed informed consent from all patients. Patients who are diagnosed cases of IPF as per ATS/ERS guideline 2011, aged above 18 years and those who were willing to give informed written consent were included in our study.

The detailed clinical history including respiratory complaints and duration, past medical history, family history and other illness was collected. The physical examination of the subjects was done. The subject's laboratory investigation included complete blood count, chest radiograph, urine routine and microscopic evaluation, spirometry with bronchodilator reversibility and DLCO testing, arterial blood gas measurements, and antinuclear antibody (ANA) test were performed. Patients who progressed to respiratory failure were evaluated for different causes like acute exacerbation of IPF, infections, heart failures, ischemic heart disease, pneumothorax, pulmonary thromboembolism, pulmonary artery hypertension and Bronchogenic Carcinoma.

\section{Sample size calculation}

Sample size was calculated using the following formula: ${ }^{7}$

$$
n=\frac{Z^{2} P(1-P)}{d^{2}}
$$

Where we expected respiratory failure in $70 \%$ of DPLD patients $(\mathrm{p})=70 \%$, with a precision error of estimation (d) set at 0.14 (or $20 \%$ of p), alpha set at 0.05 , the expected sample size was 40 cases.

\section{Statistical analysis}

The data was analyzed using ( $\mathrm{R}$ software 3.1.2) SPSS 17.0. Continuous data were presented as mean \pm SD (standard deviation) and the categorical variables were presented as percentages with absolute numbers. The association between categorical variables was analysed using chi-square test or Fisher's exact test. Continuous data were compared using t-test. $\mathrm{P}<0.05$ was considered as statistically significant.

\section{RESULTS}

The study comprised of 44 subjects diagnosed with IPF including 28 females (63.64\%). Majority of the subjects belongs to age group of 61 to 70 years $(36.36 \%)$. Two patients $(4.55 \%)$ had family history of IPF. Majority of patients in the sample presented with breathlessness $(95.45 \%)$ and cough $(81.82 \%)$. Two $(4.54 \%)$ of the 44 patients were smokers. Three patients $(6.8 \%)$ were ANA (antinuclear antibody) positive. As per chest radiograph findings, reticular shadows were identified in 38 (88.64\%) patients and reticular shadows with honeycombing were observed in $5(11.36 \%)$. DLCO in $40.91 \%$ of the sample was $<60 \%$, in $34.09 \%$ the capacity was between $60 \%$ and $80 \%$, and in $20.45 \%$ of the sample, DLCO was $>80 \%$ (Table 1 ).

Fourteen patients (31.82\%) presented with type 2 respiratory failure. The causes of type 2 respiratory failure were acute exacerbation of IPF in 5 patients $(35.71 \%)$, infection in 2 subjects $(14.29 \%)$, heart failure and ischemic heart disease in 2 patients (14.29\%), pulmonary embolism in 3 patients $(21.43 \%)$, pneumothorax in $1(7.14 \%)$ patient, and surgical lung biopsy in $1(7.14 \%)$ patient (Table 2).

All the 14 with type 2 respiratory failure patients were on ventilation, out of which 9 patients $(64.29 \%)$ were on non-invasive mechanical ventilation (NIV) and 5 patients $(35.71 \%)$ were on invasive mechanical ventilation (IMV). 


\begin{tabular}{|c|c|c|}
\hline Factors & Sub-category & Count (\%) \\
\hline \multirow{5}{*}{ Age group } & $<50$ years & $9(20.45 \%)$ \\
\hline & $51-60$ years & $9(20.45 \%)$ \\
\hline & $61-70$ years & $16(36.36 \%)$ \\
\hline & $71-80$ years & $9(20.45 \%)$ \\
\hline & $>80$ years & $1(2.27 \%)$ \\
\hline \multirow[t]{2}{*}{ Gender } & Female & $28(63.64 \%)$ \\
\hline & Male & $16(36.36 \%)$ \\
\hline Family & Yes & $2(4.55 \%)$ \\
\hline History & No & $42(95.45 \%)$ \\
\hline \multirow[t]{7}{*}{ Symptoms } & Breathlessness & $42(95.45 \%)$ \\
\hline & Cough & $36(81.82 \%)$ \\
\hline & Sputum & $11(25 \%)$ \\
\hline & Chest pain & $6(13.64 \%)$ \\
\hline & Hemoptysis & $0(0 \%)$ \\
\hline & Wheeze & $1(2.27 \%)$ \\
\hline & Other symptoms & $27(61.36 \%)$ \\
\hline \multicolumn{2}{|l|}{ Smoking } & $2(4.55 \%)$ \\
\hline \multicolumn{2}{|l|}{ Clubbing } & $6(13.64 \%)$ \\
\hline \multicolumn{2}{|l|}{ Edema } & $7(15.91 \%)$ \\
\hline \multirow[t]{2}{*}{ ANA status } & Positive & $3(6.82 \%)$ \\
\hline & Negative & $41(93.18 \%)$ \\
\hline \multirow{2}{*}{$\begin{array}{l}\text { Chest X-ray } \\
\text { findings }\end{array}$} & $\mathrm{B} / \mathrm{L}$ reticular shadows & $39(88.64 \%)$ \\
\hline & $\begin{array}{l}\mathrm{B} / \mathrm{L} \text { reticular shadows } \\
\text { with honeycombing }\end{array}$ & $5(11.36 \%)$ \\
\hline \multirow[t]{3}{*}{ DLCO } & $<60$ & $18(40.91 \%)$ \\
\hline & $60-80$ & $15(34.09 \%)$ \\
\hline & $>80$ & $9(20.45 \%)$ \\
\hline \multicolumn{2}{|c|}{ Type 2 respiratory failure } & $14(31.82 \%)$ \\
\hline
\end{tabular}

\section{Table 2: Causes of type 2 respiratory failure}

\begin{tabular}{lc}
\hline Causes $\mathbf{(} \mathbf{n}=\mathbf{1 4})$ & Count $\mathbf{( \% )}$ \\
\hline Acute exacerbation of IPF & $5(35.71 \%)$ \\
Infections & $2(14.29 \%)$ \\
Bronchial carcinoma & $0(0 \%)$ \\
Heart failure and IHD & $2(14.29 \%)$ \\
Pulmonary embolism & $3(21.43 \%)$ \\
Pneumothorax & $1(7.14 \%)$ \\
Surgical lung biopsy & $1(7.14 \%)$ \\
Other causes & 0 \\
\hline
\end{tabular}

IPF: Idiopathic pulmonary fibrosis; IHD: Ischemic heart disease

Eight out of 9 patients on NIV survived. All 5 patients on IMV expired (Table 3).

Mean $\mathrm{pH}(\mathrm{p}=0.588), \mathrm{pCO} 2(\mathrm{p}=0.861)$ and duration of illness $(p=0.303)$ did not significantly differ between NIV and IMV groups (Table 4).

Table 5 presents the management modalities applied in the treatment of IPF patients.

\section{DISCUSSION}

DPLD comprises of a multiple group of diseases characterized by swelling of lung interstitium or parenchyma

\begin{tabular}{lccc}
\multicolumn{3}{l}{$\begin{array}{l}\text { Table 3: Association of outcome with type of } \\
\text { mechanical ventilation }\end{array}$} & \multicolumn{2}{c}{ Outcome } \\
\hline \multirow{2}{*}{$\begin{array}{l}\text { Type of } \\
\text { ventilation }\end{array}$} & Total & Survived & Expired \\
\hline NIV & & $8(88.89 \%)$ & $1(11.11 \%)$ \\
IMV & $5(35.71 \%)$ & $0(0 \%)$ & $5(100 \%)$ \\
\hline
\end{tabular}

NIV: Non-invasive mechanical ventilation; IMV: Invasive mechanical ventilation

\begin{tabular}{|c|c|c|c|}
\hline Parameters & NIV & IMV & $P$ Value \\
\hline $\mathrm{pH}$ & $7.26 \pm 0.16$ & $7.22 \pm 0.062$ & 0.588 \\
\hline $\mathrm{pCO} 2$ & $68.57 \pm 26.52$ & $70.78 \pm 7.81$ & 0.861 \\
\hline $\begin{array}{l}\text { Duration of } \\
\text { illness (years) }\end{array}$ & $3.0 \pm 1.34$ & $3.80 \pm 1.30$ & 0.303 \\
\hline
\end{tabular}

\begin{tabular}{lc}
$\begin{array}{l}\text { Table 5: Management modalities applied in the } \\
\text { treatment of IPF patients }\end{array}$ \\
\hline Modalities & Absolute numbers (\%) \\
\hline Steroids & $24(54.55 \%)$ \\
Antibiotics & $8(18.18 \%)$ \\
Diuretics & $8(18.18 \%)$ \\
Anticoagulants & $3(6.82 \%)$ \\
Intercostal tube & $1(2.27 \%)$ \\
\hline
\end{tabular}

and varying degrees of fibrosis. IPF is the commonest type of DPLD. ${ }^{8}$ The current research study was designed to identify the causes of type 2 respiratory failure and the treatment modalities applied to manage them.

In this study, most $(36.36 \%)$ of the patients were in the age group of $61-70$ years. A systematic review by Raghu et al concluded that frequency of IPF cases was increased with age and is reported frequently after 50 years of age. ${ }^{9}$ Most patients enrolled in the study were women $(63.64 \%)$. Previous studies report higher incidence of IPF in men. ${ }^{10-12}$ The $4.45 \%$ of the total study population had history of smoking. Case control study by Baumgartner et a1 reported 1.7-times increase in the chances of developing IPF and Simsek et al., observed $72 \%$ of IPF cases had a history of smoking while $63 \%$ in the control group were smokers. ${ }^{12,13}$ It was observed that $4.5 \%$ of patients had family history of IPF. Familial IPF is associated with severe symptoms such as shortness of breath, tiredness, weight loss, and onset at younger age. Evidence of lung inflammation has also been observed in unaffected family members of those with familial IPF. These results present compelling evidence supporting the existence of genetic factors that predispose to IPF. ${ }^{14}$ However, specific genetic factors of IPF are not known.

In this study, $13.6 \%$ and $15.9 \%$ of the total study population presented with clubbing and edema, respectively, which 
were in concordance with the existing literature. ${ }^{15,16}$ Most common abnormality seen in IPF patients was reticular abnormality (pattern seen on the chest radiograph) and it was reported that honeycombing (patches of cystic spaces in lungs) develops in later stages of disease. Our study found bilateral reticular shadows in about $88.6 \%$ patients and $11.4 \%$ patients had bilateral reticular shadows along with honeycombing. Maheshwari et al reported identification of reticular shadows in the chest X-ray of $92 \%$ patients with IPF. ${ }^{17}$ Kundu et al., reported identification of reticular shadows in the chest X-ray of $100 \%$ patients with IPF. ${ }^{18} \mathrm{~A}$ study by Wyuts et al., concluded that $67 \%$ of patients with IPF had honeycombing. ${ }^{19}$

About 32\% (14 patients) developed type 2 respiratory failure and the causes were acute exacerbation of IPF $(35.71 \%)$, pulmonary embolism $(21.43 \%)$, heart failure $(14.29 \%)$, infections (14.29\%), pneumothorax (7.14\%), and surgical lung biopsy (7.14\%). Smith et al 2021 reported pneumonia $(56.3 \%)$, IPF exacerbation $(62.5 \%)$, cardiac disorders $(25 \%)$, pulmonary embolism $(2.1 \%)$, sepsis $(8.3 \%)$, and others $(8.3 \%)$ as reasons of respiratory failure. ${ }^{20}$

Moreover, patients were treated with steroids (54.5\%), diuretics $(18.2 \%)$ and antibiotics $(18.2 \%)$, anticoagulants $(6.8 \%)$ and intercostal tube drainage $(2.3 \%)$ for the treatment of type 2 respiratory failure. Smith et al 2021 reported the use of steroids $(79.2 \%)$, vasopressors $(14.6 \%)$, and hemodialysis $(4.2 \%){ }^{20}$

Furthermore, all 14 patients with respiratory failure were on artificial ventilation, out of which 9 patients $(64.29 \%)$ were on NIV and 5 patients $(35.71 \%$ ) were on IMV. Eight out of 9 patients on NIV survived. All 5 patients on IMV expired. Luo et al 2020, investigated the clinical outcomes of mechanical ventilation. Similar results on mortality rates associated with NIV and IV ventilation were reported $(62 \%$ vs $88 \%){ }^{21}$

This study summarizes the etiology of type 2 respiratory failure in IPF patients and management strategies to treat complications of IPF. The study has a few limitations. It was a single-center study. Other limitations include a small sample size and a referral bias. Patients referred from a specialized center tend to have complex presenting features and that could have affected prognosis of patients.

\section{CONCLUSION}

Patients were treated with steroids, diuretics, antibiotics, anticoagulants, and intercostal tube drainage based on, underlying etiology. Considering the higher mortality rate associated with IMV, the study concludes that NIV is a better technique than IMV for improving patient outcome and their overall management. NIV may thus be effectively used and further modified for improving the treatment outcome in patients with IPF and avoiding any aggressive therapeutic approaches.

\section{REFERENCES}

1. Fiddler $\mathrm{C}$ and Parfrey $\mathrm{H}$. Diffuse parenchymal lung disease. Medicine. 2016; 44(6):359-366.

https://doi.org/10.1016/j.mpmed.2016.03.014

2. Indian Chest Society [cited on 2020 Nov 27]. Available from: www.ildindiaregistry.com

3. Raghu G, Remy-Jardin M, Myers JL, Richeldi L, Ryerson CJ, Lederer DJ, et al. Diagnosis of idiopathic pulmonary fibrosis. An official ATS/ERS/JRS/ALAT clinical practice guideline. American Journal of Respiratory and Critical Care Medicine. 2018; 198(5): e44-e68.

https://doi.org/10.1164/rccm.201807-1255ST

4. Johannson KA and Collard HR. Acute exacerbation of idiopathic pulmonary fibrosis: a proposal. Current Respiratory Care Reports 2013; 2(4):233-240.

https://doi.org/10.1007/s13665-013-0065-x

5. Balamugesh T and Behera D. Idiopathic pulmonary fibrosis. Journal of The Association of Physicians of India. 2007; 55:363-370.

6. Faverio P, De Giacomi F, Sardella L, Fiorentino G, Carone M, Salerno $F$, et al. Management of acute respiratory failure in interstitial lung diseases: overview and clinical insights. BMC Pulmonary Medicine. 2018; 18(1):1-3.

https://doi.org/10.1186/s12890-018-0643-3

7. Yadav $\mathrm{H}$ and Srivastava R. Clinicoradiological and demographic pattern in diffuse parenchymal lung diseases: An observational study. International Journal of Medical Research and Review. 2018; 6(06):308-314.

https://doi.org/10.17511/ijmrr.2018.i06.03

8. Raghu G, Collard HR, Egan JJ, Martinez FJ, Behr J, Brown KK, et al. An official ATS/ERS/JRS/ALAT statement: idiopathic pulmonary fibrosis: evidencebased guidelines for diagnosis and management. American Journal of Respiratory and Critical Care Medicine. 2011; 183(6):788-824.

https://doi.org/10.1164/rccm.2009-040GL

9. Jafri S, Ahmed N, Saifullah N and Musheer M. Epidemiology and Clinico-radiological features of Interstitial Lung Diseases. Pakistan Journal of Medical Sciences. 2020; 36(3):365. https://doi.org/10.12669/pjms.36.3.1046

10. Gribbin J, Hubbard RB, Le Jeune I, Smith CJ, West J and Tata LJ. Incidence and mortality of idiopathic pulmonary fibrosis and sarcoidosis in the UK. Thorax. 2006; 61(11):980-985. https://doi.org/10.1136/thx.2006.062836

11. Von Plessen $C$, Grinde $\varnothing$ and Gulsvik A. Incidence and prevalence of cryptogenic fibrosing alveolitis in a Norwegian community. Respiratory Medicine. 2003; 97(4):428-435. https://doi.org/10.1053/rmed.2002.1466

12. Baumgartner KB, Samet JM, Coultas DB, Stidley CA, Hunt WC, Colby TV, et al. Occupational and environmental risk factors for idiopathic pulmonary fibrosis: a multicenter case-control study. American Journal of Epidemiology. 2000; 152(4):307-315. https://doi.org/10.1093/aje/152.4.307

13. Şimşek C, Sarı G, Akgündüz B, Ağaçkıran $Y$, Türksoy VA, 
Tezer N, et al. Essential trace element levels in lung tissue of idiopathic pulmonary fibrosis patients: A case control study. Trace Elements and Electrolytes. 2020; 37(4):188.

https://doi.org/10.5414/TEX01633

14. Sadraei NH, Riahi T and Masjedi MR. Idiopathic pulmonary fibrosis in a referral center in Iran: are patients developing the disease at a younger age? Archives of Iranian Medicine. 2013; 16(3).

15. dos Santos MY, Prada VR and Ghisi CU. Familial pulmonary fibrosis-a case report. Revista de Medicina. 2020; 99(Suppl):32. https://doi.org/10.11606/issn.1679-9836.v99i3p272-277

16. Ravaglia C, Bosi M, Wells AU, Gurioli C, Gurioli C, Dubini A, et al. Idiopathic pulmonary fibrosis: prognostic impact of histologic honeycombing in transbronchial lung cryobiopsy. Multidisciplinary Respiratory Medicine. 2019; 14(1):1-7.

https://doi.org/10.1186/s40248-019-0170-y

17. Maheshwari U, Gupta D, Aggarwal AN and Jindal SK Spectrum and diagnosis of idiopathic pulmonary fibrosis. Indian Journal of Chest Diseases and Allied Sciences. 2004;46(1):23-26.

18. Kundu S, Mitra S, Ganguly J, Mukherjee S, Ray S and Mitra R Spectrum of diffuse parenchymal lung diseases with special reference to idiopathic pulmonary fibrosis and connective tissue disease: An eastern India experience. Lung India. 2014; 31(4):354-360.

https://doi.org/10.4103/0970-2113.142115

19. Wuyts WA, Cavazza A, Rossi G, Bonella F, Sverzellati N, Spagnolo P. Differential diagnosis of usual interstitial pneumonia: when is it truly idiopathic? The European Respiratory Review. 2014; 23(133):308-319. https://doi.org/10.1183/09059180.00004914

20. Smith RA, Sathananthan $M$, Kaur $P$, Jeganathan $N$. The characteristics and outcomes of patients with idiopathic pulmonary fibrosis admitted to the ICU with acute respiratory failure. Heart Lung. 2021; 50(1):192-196. https://doi.org/10.1016/j.hrtlng.2020.05.006

21. Luo Z, Yang L, Liu S, Hu Y, Cao Z, Zhu J, et al. Mechanical ventilation for acute respiratory failure due to idiopathic pulmonary fibrosis versus connective tissue disease-associated interstitial lung disease: Effectiveness and risk factors for death. The Clinical Respiratory Journal. 2020;14(10):918-932. https://doi.org/10.1111/crj.13223

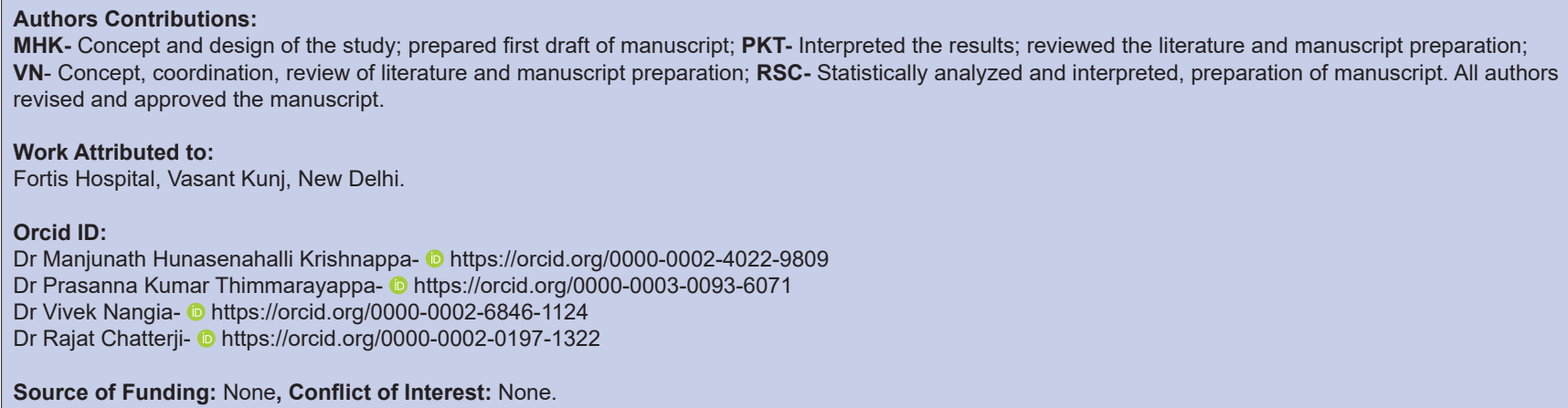

